\title{
Experiencing Transanal TME with a Cadaveric Model
}

\author{
Min Ki Kim, M.D. Ph.D. ${ }^{1}$, Yoon Suk Lee, M.D., Ph.D. ${ }^{1}$, Hyung-Jin Kim, M.D., Ph.D. ${ }^{2}$, Suk-Hwan Lee, M.D., Ph.D. ${ }^{3}$, \\ Jun-Gi Kim, M.D., Ph.D. ${ }^{4}$, SIMPLE ISIngle port versus MultiPort trial Laparoscopic surgery) Trial Study Group \\ 'Department of Surgery, Seoul St. Mary's Hospital, College of Medicine, The Catholic University of Korea, Seoul, '2Department of Surgery, St. Vincent \\ Hospital, College of Medicine, The Catholic University of Korea, Seoul, ${ }^{3}$ Department of Surgery, Kyung Hee University at Gangdong, Kyung Hee University \\ School of Medicine, Seoul, ${ }^{4}$ Department of Surgery, College of Medicine, The Catholic University of Korea, Seoul, Korea
}

\begin{abstract}
Transanal total mesorectal excision (taTME) is known to be a novel surgical approach for patients who are difficult to resolve with the traditional trans-abdominal approach. However, most of the colorectal surgeons are unfamiliar with the technique, which can lead to serious complications such as urethral injury. Hence, training through the fresh frozen cadaver has been gradually included in the formal taTME training course. The authors trained the taTME procedure with two cadavers in 2016. Two surgeons who were experts in trans-anal minimally invasive surgery and had minimal experiences in taTME performed the procedure. The total procedure time from the purse string suture to the anterior communication took about 65 minutes. The procedure proceeded well without any inadvertent injury to anatomic structures. The usefulness of the cadaveric model in training taTME was confirmed and the experience of single port surgery and trans-anal operation before the cadaveric training is considered to be important.
\end{abstract}

Keywords: Rectal neoplasms, Cadaver, Surgery, Laparoscopy

Supplementary video file: This article contains supplementary material (https://doi.org/10.7602/ jmis.2017.20.4.160).
Received July 12, 2017

Revised August 28, 2017

Accepted September 13, 2017

Corresponding author

Jun-Gi Kim

Department of Surgery, College of

Medicine, The Catholic University of

Korea, 222 Banpo-daero, Seocho-

gu, Seoul 06591, Korea

Tel: $+82-2-2258-2876$

Fax: $+82-2-595-2822$

E-mail: jgkim@catholic.ac.kr

This is an Open Access article distributed under the terms of the Creative Commons Attribution Non-Commercial License (http:/l creativecommons.org/licenses/by-nc/4.0/) which permits unrestricted non-commercial use, distribution, and reproduction in any medium, provided the original work is properly cited.

Copyright (C) 2017 The Journal of Minimally Invasive Surgery. All rights reserved.

\section{INTRODUCTION}

After Sylla et al. ${ }^{1}$ reported a clinical case of hybrid taTME in 2010, taTME has been actively studied as a better alternative to conventional trans-abdominal access in difficult rectal cancer surgery such as narrow pelvis, obesity, and/or bulky, low-lying tumor. However, single-port surgery technique and bottomup direction access needed in taTME procedure are difficult to learn to most colorectal surgeons who are familiar with conventional open or laparoscopic multiport top-down procedures. To overcome this steep learning curve, several training programs including cadaver workshop centered on the US and
Europe were created and operated for taTME., ${ }^{2,3}$ The authors tried to find out the feasibility of taTME procedure and cultivate the technique through the cadaveric training model.

\section{METHOD}

A workshop was held in January 2016 at the SIMPLE (SIngle port versus MultiPort trial Laparoscopic surgery) trial researchers' group supported by the KSELS (Korean Society of Endoscopic \& Laparoscopic Surgeons). Among the two cadavers used in the workshop, the video related to this paper used the fresh frozen cadaver of a 71 year-old male without 
any scar. After fixation of the body in the lithotomy position, anal retraction was performed. We used TEO (Karl Storz Endoskope Co., Germany) trans-anal access platform, and pressure for pneumopelvis was set to $1 \sim 2 \mathrm{mmHg}$ without using AirSeal insufflation system (ConMed Inc., USA). Two operators involved in the procedure. They were experts in transanal minimally invasive surgery, but their taTME experiences was less than 10 cadaveric cases each with no clinical case. Total operation time from anal retraction to the anterior communication was about 65 minutes. There was active discussion during and after the procedure among workshop participants. Dissection was performed in the order of posterior, anterior and lateral side at the same horizontal level. When the circumferential dissection is complete at the same horizontal level, the dissection field was moved from the distal to the proximal direction and the circumferential dissection is started again.

The posterior side, up to about $5 \mathrm{~cm}$ from the anal verge is a kind of bare area with little blood vessels or nerves. However, since the posterior midline is a thick fibrous tissue, both sides of the posterior should be dissected first and then approach the midline. The dissection proceeds along the levator ani muscle. With a gauze, specimen lifting and maintaining plane are easy. At about $6 \sim 8 \mathrm{~cm}$ from the anal verge, the bow shaped S2/S3 inferior hypogastric routes would be exposed. If the dissection proceeds to the S1 and S2 level, the visceral and parietal fascia fuses, and the angle steeps back to the upper side. Therefore, the dissection becomes difficult, and the dissection above this level may be preferable to be performed by trans-abdominal approach team.

The mesorectum is much thinner in the anterior side. Careful dissection is needed to maintain exact plane, and if the surgeon penetrates the Denonvilliers' fascia, the urethral injury is imminent. The neurovascular bundle of Walsh is located in the way of wrapping the prostate from both sides during taTME. If the dissection is on the wrong plane, this structure may be injured, and bleeding not easily controlled by electrocautery will occur. Once the prostate is identified, progression to the seminal vesicle is relatively easy. In female cases, haptic feedback by palpating the vagina can reduce the possibility of injury to the posterior vaginal wall. Communication with the peritoneal cavity occurs first on the anterior side. After the communication, the pneumopelvis becomes unstable so that much of taTME as possible should be performed before that.

Since it is relatively difficult to find the proper plane of the lateral side, dissect the posterior and anterior sides first and then connect the remaining lateral sides. There is a pelvic muscular side wall, and it should be dissected inwards without damaging it. If it is the correct plane, bilateral pillars or tonsils of adipose tissue can be observed at the level of the mid- rectum. Lateral to this structure, there are also areolar tissue, but following this wrong plane can lead to injure nerve and vascular structures. During this process, pelvic splanchnic nerves come out and keep the dissection plane inward.

The procedure proceeded well in this cadaveric workshop without any inadvertent injury to anatomic structures.

\section{DISCUSSION}

Fresh frozen cadaver has the advantage of preserving almost the characteristics of living body, unlike fixed cadaver which uses formalin. It is known to increase performance and shorten the learning curve in taTME, because the anatomical structure and tactile sensation are most similar to the human body and there is less bleeding.

The cadaveric training model of taTME in Korea was reported by Kim et al. ${ }^{5}$ but this is the first time to present this novel approach in video demonstration. The surgeons seemed to be able to proceed with the procedure without complications even though they had only a little experience with taTME because they were previously familiar with trans-anal minimally invasive surgery. We performed scissor dissection as much as possible and minimize the use of electrocautery to maintain a good visual field.

Because the cadaver is relatively expensive, when preparing a cadaver workshop, you must clarify its purpose and plan the process in detail. For example, you should specify from which part of taTME to what part you want to proceed, whether you can do other procedure for training if time is left, or in what order the training procedures should be done depending on the need of the laparoscopy or position of the cadaver. In addition, the surgeon should have accumulated a lot of experience in trans-anal procedures and single-port laparoscopic surgery to earn maximal achievement in cadaveric taTME. If preparation is enough, taTME training with cadaveric model would be the most effective and efficient one.

\section{ACKNOWLEDGMENTS}

Dr. HJ Kim of SIMPLE Trial Study Group provided photos and other related materials.

Transanal total mesorectal excision cadaver workshop received financial support from the Korean Society of Endoscopic \& Laparoscopic Surgeons (Seongnam-si, Gyeonggi-do, republic of Korea).

\section{REFERENCES}

1) Sylla P, Rattner DW, Delgado S, Lacy AM. NOTES transanal rectal cancer resection using transanal endoscopic microsurgery and 
laparoscopic assistance. Surg Endosc 2010;24:1205-1210.

2) Penna M, Whiteford M, Hompes R, Sylla P. Developing and assessing a cadaveric training model for transanal total mesorectal excision: initial experience in the UK and USA. Colorectal Dis 2017;19:476-484.

3) McLemore EC, Harnsberger CR, Broderick RC, et al. Transanal total mesorectal excision (taTME) for rectal cancer: a training pathway. Surg Endosc 2016;30:4130-4135.
4) Foster JD, Gash KJ, Carter FJ, et al. Development and evaluation of a cadaveric training curriculum for low rectal cancer surgery in the English LOREC National Development Programme. Colorectal Dis 2014;16:0308-319.

5) Kim MJ, Park JW, Ha HK, et al. Initial experience of transanal total mesorectal excision with rigid or flexible transanal platforms in cadavers. Surg Endosc 2016;30:1640-1647. 